\title{
Digital ischaemia: a rare but severe complication of jellyfish sting
}

\author{
Stacey C Lam, YW Hung *, Esther CS Chow, Clara WY Wong, WL Tse, PC Ho
}

\begin{abstract}
A B S T R A C T
We report a case of digital ischaemia in a 31-year-old man who presented with sudden hand numbness, swelling, and cyanosis 4 days after a jellyfish sting. This is a rare complication of jellyfish sting, characterised by a delayed but rapid downhill course. Despite serial monitoring with prompt fasciotomy and repeated debridement, he developed progressive ischaemia in multiple digits with gangrenous change. He subsequently underwent major reconstructive surgery and aggressive rehabilitation. Although jellyfish stings are not uncommon, no severe jellyfish envenomation has been reported in the past in Hong Kong and there has not been any consensus on the management of such injuries. This is the first local case report of jellyfish sting leading to serious hand complications. This case revealed that patients who
\end{abstract}

sustain a jellyfish sting deserve particular attention to facilitate early detection of complications and implementation of therapy.

\section{Hong Kong Med J 2014;20:460-3}

\section{DOI: 10.12809/hkmj134155}

\section{SC Lam, BS, MB, ChB}

YW Hung *, FHKCOS, FHKAM (Orthopaedic Surgery)

ECS Chow, FHKCOS, FHKAM (Orthopaedic Surgery)

CWY Wong, FHKCOS, FHKAM (Orthopaedic Surgery)

WL Tse, FHKCOS, FHKAM (Orthopaedic Surgery)

PC Ho, FHKCOS, FHKAM (Orthopaedic Surgery)

Division of Hand and Microsurgery, Department of Orthopaedics, Prince of Wales Hospital, Shatin, Hong Kong

* Corresponding author: ywhung@ort.cuhk.edu.hk

\section{Case report}

Our patient was a 31-year-old man with unremarkable past health. He was swimming in the waters of Phuket, Thailand, when he experienced a sudden, intense burning pain in his right arm and right thigh. He spotted a jellyfish in the water after the incident. After getting out of the water, he noticed immediate reddening and swelling over the right thigh and right upper limb (from elbow down to the hand). No systemic symptoms were reported. The locals gave him some water to irrigate the sting site and slathered a soothing cream on it. He was then admitted to the local hospital and given a dose of steroids.

The next day, he was discharged from the local hospital and returned to Hong Kong. He was admitted to the Department of Orthopaedics and Traumatology of Prince of Wales Hospital, Hong Kong, in July 2013. It was the second day after his injury, and his right arm was swollen up to the midarm, and there were multiple maculopapular lesions over his right thigh and arm (Fig 1a, 1b). The injury site in the right forearm was explored the same day, revealing healthy subcutaneous tissue, fascia, and muscle (without features of necrotising fasciitis). Wound swab culture was negative.

On the fourth day after the sting, he experienced sudden onset of numbness and pain in his right hand which rapidly progressed to almost complete loss of sensation. The swelling in the right arm and forearm also increased. The skin was cold with cyanotic change in all fingers and the thumb; capillary refill was sluggish ( $>4$ seconds) but with preserved turgor (Fig 1c). The radial pulse was not palpable. Compartment pressure measured with Stryker needle revealed superficial flexor compartment pressure of $35 \mathrm{~mm} \mathrm{Hg}$, deep flexor compartment pressure of $25 \mathrm{~mm} \mathrm{Hg}$, and extensor compartment pressure of $22 \mathrm{~mm} \mathrm{Hg}$.

Immediate fasciotomy of the right forearm was done, revealing subcutaneous oedema but no evidence of myonecrosis. Arteriotomy was not performed in view of return of palpable radial and ulnar pulse. Again, wound swab culture revealed no bacterial growth. Biopsy revealed muscle necrosis and infiltrate with white cells (predominantly polymorph). Postoperatively, he was put in a warm room with adequate fluid replacement and started on subcutaneous fraxiparine.

Despite wound debridement and aggressive medical treatment, 2 weeks after his initial insult, his right hand circulation remained sluggish, with progressive gangrenous change in the distal phalanges of the thumb, index finger, middle finger, half of the ring finger, and dorsum of the hand (Fig 1d, 1e). Computed tomography angiogram showed that the brachial artery was patent down to the palmar arch level, suggesting distal small vessel disease. As such, his gangrene would not be amenable to surgical intervention. Finally, he had a staged reconstructive 
surgery with distal amputation of his distal index finger and thumb; a groin flap (distant pedicle flap) was used to cover the major skin defect over the dorsum of the hand and the thumb (Fig 1f, 1g). With careful reconstructive surgery and aggressive rehabilitation, 9 months after the incident, his right hand regained movement, although it remained functionally impaired with significant stiffness and numbness (Fig 1h).

\section{Discussion}

Jellyfish belong to a family of Cnidaria found all over the world. There are more than 2000 different types of jellyfish, of which approximately 70 are toxic to humans. ${ }^{1}$ The pathophysiology of jellyfish sting is a combination of toxin and immunological response (immediate allergic reaction and delayed reaction). ${ }^{2}$ The toxins are composed of a mixture of polypeptides and enzymes, leading to local or systemic inflammatory responses. ${ }^{2}$ There has also been a report on toxins causing platelet aggregation. ${ }^{3}$ Hence, the physiological response of jellyfish sting

\section{手指缺血：被水母蟄傷後一種罕見但嚴重的 併發症}

林懿德、洪煜華、周靜珊、黃詠儀、謝永廉、何百昌 本文報告一名 31 歲男子被水母蟄傷四日後手指缺血的情況。病人出 現手部麻木、腫脹和呈現青紫色。這是被水母蟄傷後一種罕見的併發 症, 特點是病徵延遲出現, 但病情惡化的速度相當快。儘管連續監控 病情, 並及時施行筋膜切開術和進行清創多次, 病人的手指仍有進 展性缺血的現象, 多隻指頭更出現壞疽情況。隨後, 病人須接受大型 重建手術和積極的康復治療。水母蜇傷的情況很常見, 過往香港亦沒 有被水母蟄傷而引發嚴重事件的報導, 不過至今對於類似病例的治療 方法尚未達成共識。這是本港首宗因被水母蟄傷而導致嚴重併發的病 例。本病例表明被水母蟄傷的患者須格外留意, 以便及早發現併發症 並尋求治療。

depends on the species of jellyfish and the toxins they release.

The toxin of Cnidaria is located in the

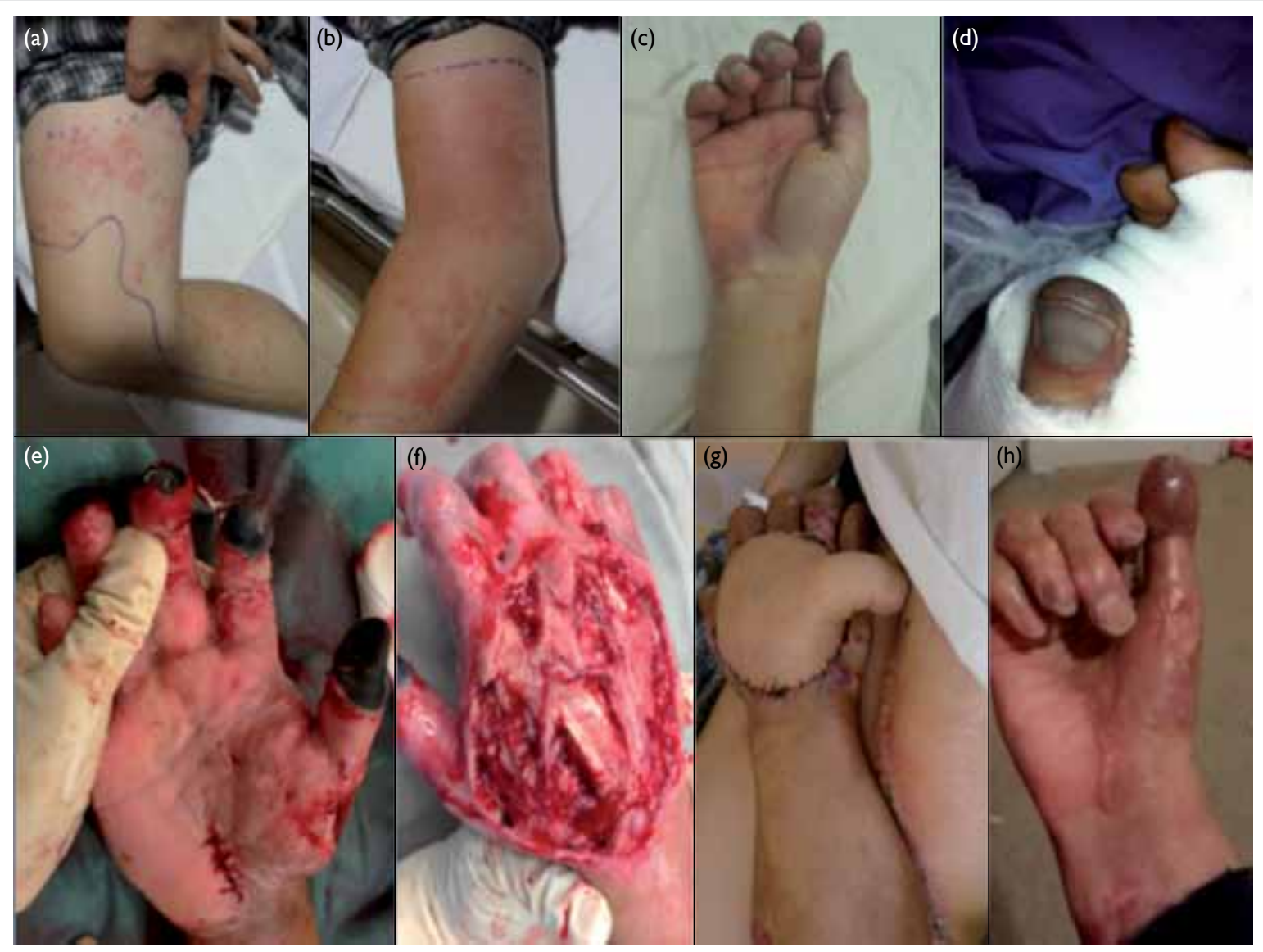

FIG I. Serial photos showing progressive digital gangrene and large skin defect after repeated debridement Typical lesion after jellyfish sting over (a) right thigh, (b) elbow, and (c) hand on day 2 after injury: linear; papular whip-like dermatitis ('tentacle print'). (d) Finger tip with cyanotic changes on day 8 after injury. (e) Well-demarcated gangrenous change over finger tips on day 15 after injury. $(\mathrm{f})$ Extensive skin defect with expose tendon after debridement on day 17 after injury. (g) Reconstruction included a two-stage operation with groin flap to cover the dorsum of hand and a second groin flap to cover gangrene tip (6 weeks after injury). (h) Outcome (attempt to make tight fist) after multiple major reconstruction ( 8 months after injury) 
cnidocytes, which are stinging cells composed of organelles called 'nematocysts'. Nematocysts are present on the outer surfaces of tentacles or near the mouth. These are released when the victim's skin is in contact with jellyfish, injecting the venom into the victim via a thread tube, sufficient to penetrate the dermis of human skin. ${ }^{2}$

The majority of jellyfish stings are mild with local skin reactions. The usual presentation is a painful papular-urticaria at site of contact, which looks like multiple whip-like eruptions. This is compatible with the sting on the right leg in our case, with a linear whip-like 'tentacle print.' Lesions can last for minutes or hours. Other local reactions also include hyperhidrosis of skin, lymphadenopathy, fat atrophy, vasospasm, gangrene, and contracture. Systemic reactions-including gastro-intestinal symptoms, cardiac arrest, respiratory arrest and anaphylactic shock-are rare but not impossible. ${ }^{2}$

Hong Kong is a city surrounded by ocean. Many people enjoy recreational water sports and, thus, injury related to marine life is unavoidable. The latest annual report by the Hong Kong Poison Information Centre ranked venomous stings and bites as the seventh commonest cause of poisoning. ${ }^{4}$ This is likely an underestimation as most marine accidents are managed at the scene, and this figure only takes into account the ones reported. In the English

(a)
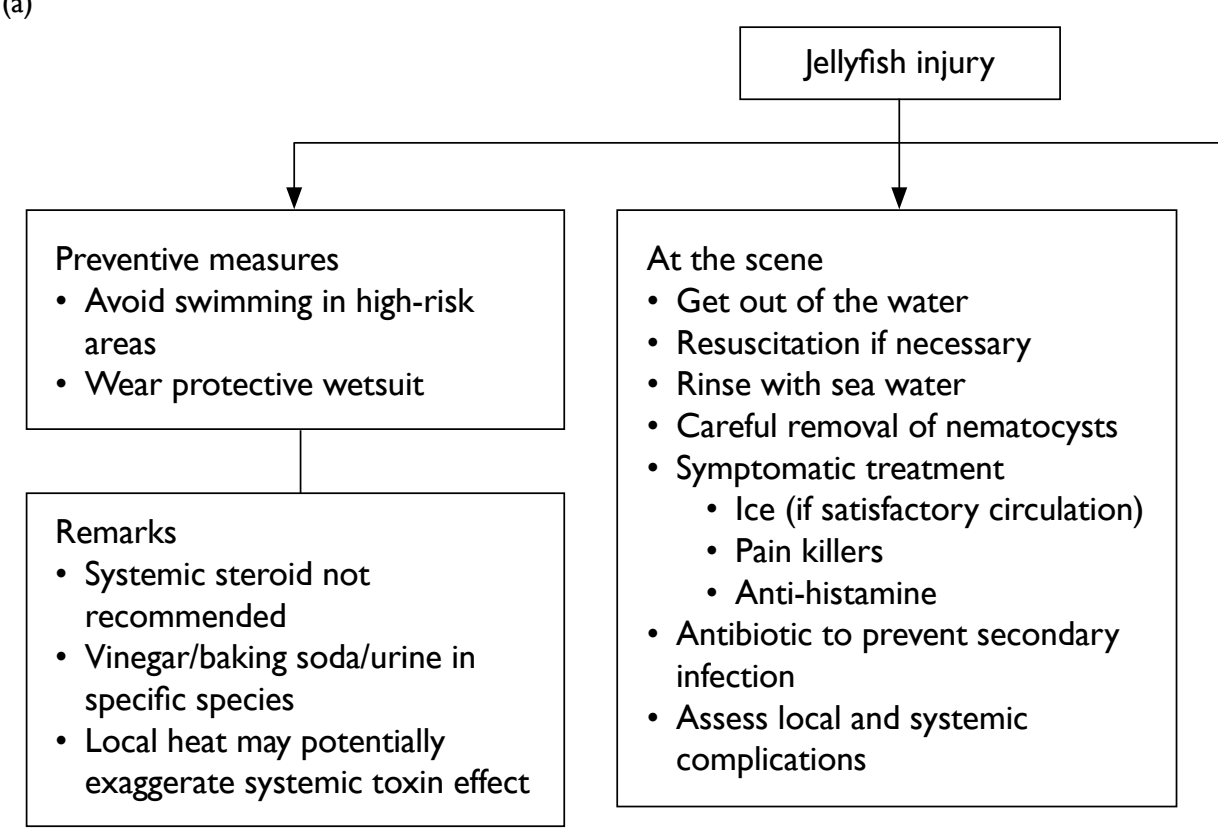

At the hospital
- Reassessment of systemic
complications
- Haemodynamic instability
- Reassessment of local
complications
- Signs of ischaemia
- Signs of compartment
syndrome

(b)

\begin{tabular}{|l|l|}
\hline $\begin{array}{l}\text { General measures } \\
\text { - Keep warm } \\
\text { vasoconstriction) } \\
\text { - Avoid diet that induces vasoconstriction: } \\
\text { caffeine, tea } \\
\text { - Positioning of limb below heart level } \\
\text { - Avoid compressive bandaging }\end{array}$ & $\begin{array}{l}\text { Specific measures } \\
\text { - Pharmacological } \\
\text { - Vasodilating agent: papaverine } \\
\text { - Anticoagulation: low-molecular-weight heparin, dextran } \\
\text { - Antiplatelet: aspirin } \\
\text { - Chemical thrombolysis: urokinase } \\
\text { - Surgical } \\
\text { - Fasciotomy if compartment syndrome } \\
\text { - Embolectomy if large-vessel thrombosis } \\
\text { - Sympathectomy if profound vasoconstriction }\end{array}$ \\
\hline
\end{tabular}

FIG 2. (a) Algorithm for prevention and treatment of jellyfish sting. (b) General measures that we recommend for limb ischaemia Note: As ischaemia related to jellyfish injury is not well understood, management needs to be tailormade for each patient 
literature, there have only been three case reports of serious jellyfish sting injuries leading to serious hand or foot complications, ${ }^{5-7}$ and our case is the first local case report. Similar to the sudden deterioration in our patient, these documented cases all reported patients who suffered from sudden oedema, cyanotic changes, and weak pulse. This occurred around 3 to 4 days after the initial insult. In addition, the case reported by Abu-Nema et $\mathrm{al}^{7}$ noted that the patient had suffered from arterial spasm complicated by thrombosis, and was subsequently treated with urokinase. Our patient shares a similar complication of vasospasm, as evidenced by patent but diminished flow in distal arteries. It may be postulated that the delayed vasospasm and possible thrombosis may have led to this rare complication of jellyfish sting. Although jellyfish injuries usually present with acute skin reactions, our patient presented with clinical deterioration of the hand on day 4 when the lower limb skin reaction was actually improving.

The differences between our case and the other case reports are in terms of alternative management modalities and complications. Our patient received fasciotomy, repeated debridement, and fraxiparine. Some of the other authors incorporated other surgical interventions such as cervicodorsal or thoracic sympathectomy and medical treatments such as dextran, prednisolone, reserpine, and urokinase in case of thrombosis. Our patient suffered from gangrenous thumb and fingers. In other case reports, reported complications ranged from a mere loss of superficial sensation, to amputation of necrotic digits with Volkmann's contracture.

Despite the adverse effects of cnidarian stings, literature on treatment is limited and often conflicting. It is difficult to perform high-quality studies with sound methodology, owing to reasons including limited number of cases and lack of randomisation. ${ }^{8}$ The majority of cases are dealt with at the scene by the general physician or accident and emergency department. It is important for us to be well equipped with management strategies for this type of injury and maintain a high level of suspicion for major complications. Our recommendations are summarised in Figure 2a.

The principles of the management of jellyfish injury are:

(1) Best treatment remains prevention of injury

(2) Alleviate the local effect of venom (pain and tissue damage)

(3) Prevent further discharge of nematocysts

(4) Control systemic reaction, including shock

Some important points need to be highlighted.

After rapid resuscitation, the next step is to remove nematocysts, if technically feasible. It is also important to note that popular home remedies such as alcohol, physical rubbing by sand, or rinsing by fresh water can actually worsen symptoms for the victim, as these may lead to a massive nematocyst discharge and toxin release. Another common folk measure is the use of vinegar or urine to inactivate the venom. Unfortunately, these two methods are not applicable to all types of jellyfish stings as different species have different toxins. We do not recommend the general population to use either vinegar or baking soda if the offending organism is not well known.

Ice therapy is safe in general for pain relief due to an unclear mechanism; whereas the application of local heat is still debated, as it may potentially induce vasodilation and a systemic toxic reaction rather than denaturation of the venom. Anti-histamine is generally safe for local symptom control and antibiotics are also recommended for secondary infection. There are no studies to support the use of systemic corticosteroids in toxic reactions. ${ }^{8}$ Antivenom exists for a species of jellyfish called Chironex fleckeri (sheep-derived whole immunoglobulin G). However, it has unknown cardiotoxic effects and, therefore, not approved or readily available. ${ }^{9}$

The underlying mechanism of local ischaemia in our case was not well understood. Toxin- and hypersensitivity-induced vasospasm and secondary thrombosis are the postulated mechanisms. The management algorithm in Figure $2 \mathrm{~b}$ is based on this postulation. As there is no standardised management in the literature, management should be tailored to the patient and should balance the risks and benefits. Further research is needed to confirm our postulation and formulate a protocol for management of jellyfish stings.

\section{References}

1. Brennan J. Jellyfish and other stingers. In: World Book's animals of the world. Chicago, IL: World Book, Inc; 2003.

2. Burnett JW, Calton GJ, Burnett HW. Jellyfish envenomation syndromes. J Am Acad Dermatol 1986;14:100-6.

3. Azuma H, Sekizaki S, Satoh A, Nakajima T, Ishikawa M. Platelet aggregation caused by a partially purified jellyfish toxin from Carybdea rastonii. Toxicon 1986;24:489-99.

4. Chan YC, Tse ML, Lau FL. Hong Kong Poison Information Centre: Annual Report 2010. Hong Kong J Emerg Medicine 2012;19:110-20.

5. Giordano AR, Vito L, Sardella PJ. Complication of a Portuguese man-of-war envenomation to the foot: a case report. J Foot Ankle Surg 2005;44:297-300.

6. Drury JK, Noonan JD, Pollock JG, Reid WH. Jelly fish sting with serious hand complications. Injury 1980;12:66-8.

7. Abu-Nema T, Ayyash K, Wafaii IK, Al-Hassan J, Thulesius O. Jellyfish sting resulting in severe hand ischaemia successfully treated with intra-arterial urokinase. Injury 1988;19:294-6.

8. Cegolon L, Heymann WC, Lange JH, Mastrangelo G. Jellyfish stings and their management: a review. Mar Drugs 2013;11:523-50.

9. Balhara KS, Stolbach A. Marine envenomations. Emerg Med Clin North Am 2014;32:223-43. 